\title{
Narsizmin İş Doyumu ve Bireysel Performans Üzerindeki Etkisi Üzerine Bir Alan Araştırması
}

\author{
DOI: $10.26466 /$ opus.534813 \\ * \\ Alper Gürer ${ }^{*}-$ Gamze Ebru Çiftçi* \\ * Dr. Öğr. Üyesi, Kırıkkale Üniversitesi, Keskin MYO, Keskin / Kırkkale / Türkiye \\ E-Posta: alpergurer@kku.edu.tr ORCID: 0000-0002-6745-7895 \\ ** Dr. Öğr. Üyesi, Hitit Üniversitesi, Sungurlu MYO, Sungurlu / Çorum / Türkiye \\ E-Posta: gamzeebruciftci@hitit.edu.tr \\ ORCID: 0000-0003-4271-6376
}

\section{Öz}

Narsizmle ilgili son yıllarda gerçekleştirilen çalışmalar narsizmin örgütsel düzeyde daha fazla araştırılması gereken bir konu olduğunu ortaya koymuştur. Toplumsal ilişkilerde önemli çatışma kaynaklarından biri olarak görülen narsistik kişilik özellikleri, örgütsel bağlamda da etkili olabilmektedir. Geçmiş araştırma bulgularn narsistik kişilik özelliklerinin örgütsel etkileri konusunda narsizmin olumlu veya olumsuz yönlerinin öne çıtı̆̆̆ farklı sonuçlar içermektedir. Bu çalışmanın amacl, narsizmin iş doyumu ve bireysel iş perormansı üzerindeki etkilerini belirlemektir. Bu amaçla çalışma narsizm ile iş doyumu ve bireysel performans arasındaki ilişkileri ortaya koyacak şekilde tasarlanmıştır. Tokat ilinde tekstil sektöründe görev yapmakta olan 311 çalışana anket uygulanarak gerçekleştirilen araştırma verilerinin analizinde frekans, t-testi, ANOVA, korelasyon ve regresyon yöntemlerinden faydalanılmıştır. Araştırma bulgularına göre narsizm ile iş doyumu ve bireysel performans arasında pozitif yönlü bir ilişki tespit edilmiştir. Çalışanların narsistik kişilik düzeyi arttıkça çalışanlarda iş doyumunun ve bireysel performansın arttığını bu çalışma sonuçları için söylemek mümkündür. Çalışmada elde edilen diğer bir sonuç, çalışanların demografik özelliklerine göre narsistik kişilik düzeylerinde bazı farklilikların olmasidir.

Anahtar Kelimeler: Narsizm, İş Doyumu, Bireysel Performans 


\title{
A Field Study on the Effect of Narcissism on Job Satisfaction and Individual Performance
}

\begin{abstract}
Recent studies on narcissism have revealed that narcissism is a subject that needs further investigation at the organizational level. Narcissistic personalit traits, which are seen as one of the important source of conflict in social relations, can be effective in organizational context. Past research findings about organizational effects of narcissistic personality traits include different results that positive and negative sides of narcissism come forward. The aim of this study is to determine the effects of narcissism oon job satisfaction and individual work performance. For this purpose, the study was designed to reveal relationships among narcissism, job satisfaction and individual performance. In this study, 311 employees who work in textile sector in Tokat province have been surveyed and frequency, $t$-tes, ANOVA, correlation and regression methods were used. According to the research findings, a positive relatilonship was found between narcissism and job satisfaction and individual performance. As the narcissistic personality level of employees increases, it is possible to say that job satisfaction and individual performance increase in employees. Another result of the study is that there are some differences in the level of narcissistic personality according to the demographic characteristics of the employees.
\end{abstract}

Keywords Narcissism, Job Satisfaction, Individual Performance 


\section{Giriş}

Narsizm, bilim tarihindeki en eski olgulardan biri olmakla beraber son yıllarda çeşitli örgütsel değişkenlerle arasındaki ilişkileri anlamaya yönelik araştırmalar sayesinde narsizme duyulan ilgi artmıştır (Ames vd., 2006, s.441; Brown vd., 2009, s.951; Emmons, 1987, s.11).

Narsizm ile ilgili genel görüş narsizmin erken çocukluk dönemlerinde oluşan bir travma sonucunda ortaya çıkan bir kiş̧ilik bozukluğu olduğu yönündedir. Amerikan Psikiyatri Birliği, Narsizm'i, kişinin kendine hayranlık duygusundan kaynaklanan sürekli bir büyüklük tavrı, beğenilme ihtiyacı ve empati eksikliğinden oluşan bir örüntü olarak açıklamaktadır (Narcissistic Personality Disorder DSM-5). Westen (1990, s.227)'e göre narsizm, "bireyin kendisiyle bilişsel olarak kurduğu duygusal bir ilişki" olarak tanımlanabilir. Narsizm, aşırı öz-odak ve kibir, sürekli olarak kendine dikkat ve hayranlık, öz-kararlılık ihtiyacı, özel bir iyilik beklentisi ve böyle bir iyilik elde etmek için başkalarını sömürme isteği ile ilişkilidir (Millon, 1981). Narsist bireyler, başkaları tarafından takdir edilme ihtiyacı içerisinde olduklarından diğer insanları kendilerine saygı duymaları ve onay vermeleri halinde değerli bulurlar (Philipson, 1985, s.214).

Campbell vd. (2011, s.269), narsizmi üç bileşeni içeren bir yapı olarak ele almışlardır; öz, kişilerarası ilişkiler ve öz düzenleme stratejileri. Öz, narsist benlik, pozitiflik, özgünlük, kibirlilik, hak sahibi olma hissi, güç ve saygı arzusudur. Kişilerarası ilişkiler, düşük düzeyde empati ve duygusal yakınlık kurma ile ilgilidir. Bu bileşen, heyecan verici ve ilgi çekici olandan manipülatif ve sömürücü olana kadar değişen sı ğ ilişkileri içerir. Öz düzenleme stratejileri, şişirilmiş benlik görüşlerini sürdürmek yönünde geliştirilen; dikkat çekmek ve hayranlık uyandırmak için fırsatlar aramak, başkalarının başarılarını kendine mal etmek ve kişisel ilişkilerde oyun oynamak gibi narsist stratejilerdir.

En sık kullanılan narsizm ölçeği olan Narsistik Kişilik Envanteri'nde (NPI) narsizm dört boyut içerisinde değerlendirilmektedir: Sömürücülük/hak iddia etme; insanları manipüle etme konusunda yetenekli bir inanç ve bunu yapma hakkı. Liderlik/otorite; birinin başkalarını etkileme konusunda olağanüstü bir yeteneğe sahip olduğu inancı, liderlik ve otorite rolleri için genel bir tercih. Üstünlük/büyüklenmecilik; birinin 
"diğerlerinden" daha iyi olduğu inanc1. Son olarak kendine yeterlilik/kendine ilgililik; yüksek bir kibir duygusu ve kendisinin özel olduğuna dair inanç (Emmons, 1987'den akt. Smith, 2017).

Emmons'un narsizm boyutlarından büyüklenmecilik (kibir), çoğu zaman narsizmle eş anlamlı anılmasına rağmen kibrin, narsizmden farklı yönleri vardır. Bu noktada, aynada kendine bakmaktan hoşlanma gibi davranışların kibrin tanımını karşılamaması, narsizmin daha çok içsel olarak hissedilmesi, bireysel düzeyde davranış bozukluğu olarak incelenmesi, işletme çalışanlarının davranışlarını açıklamaması ve kibrin daha çok sosyal ilişkilerde ortaya çıkması gibi farklılıkları sıralanabilir (Johnson vd., 2010, s.406). Özellikle narsist bireyler kendi liderlik becerilerini, görevlerini ve davranışlarını diğerlerinden daha olumlu görmekte ve tehlikede olduklarında, şiddet davranışlarında bulunmaktadırlar (Bushman ve Baumeister, 1998; Judge vd., 2006).

Toplumsal hayat içerisinde kurulan ilişkilerde narsistik kişilik özellikleri önemli çatışma kaynaklarından biri olarak öne çıkarken, örgütsel bağlamda da narsizmin etkileri görülmektedir. Örgütlerde ortaya çıkan narsist davranışlar sağlıksız ve sağlıklı olmak üzere iki farklı biçimde olabilir (Qureshi vd., 2015, s.102):

Sağlıksız Narsizm: Narsist kişiler, "insan ilişkilerinde çıkarcı davranan, samimi olmayan, karşılıklı ilişkilerde empati kuramayan, çevresindekilere karşı tolerans göstermeyen ve kendilerini herkesten üstün gören bireylerdir" (Kanten, 2014, s.163). Bu özellikleri nedeniyle, meslektaşları ile etkileşim halindeyken onlara rahatsızlık verebilir, astları üzerinde olumsuz etkiler bırakabilir ve böylece örgütlerde istenmeyen sonuçlara neden olabilirler.

İş hayatıyla ilgili gerçekleştirilen çalışmalar, narsizmi çalışanın işle ilgili tükenmişliği ile ilişkilendirmektedir (Farber, 1983). Narsist çalışanların davranışları, örgütlerin hedeflerine ulaşamamasına neden olabilmektedir (Qureshi vd., 2015, s.102). Narsizm, üretkenlik karşıtı iş davranışlarıyla doğrudan ilişkilidir (Campbell vd., 2011, s.276; Penney ve Spector, 2002, s.132). Maccoby (2003)'e göre, narsist çalışanlar örgütsel sisteme zarar verir ve örgüt iklimini bozabilirler. Bu nedenle, uzun vadede süreklilik arz eden bir narsist davranışın, sürdürülebilir bir örgüt performansına ulaşmak için gerekli olan örgüt iklimi yaratmada başarısızlığa yol açması mümkündür (Higgs, 2009, s.172). Narsistik kişilik özelliğine 
sahip çalışanlar, sahip oldukları kibir, güç açlığı, empati eksikliği vb. olumsuz kişilik özelliklerinden dolayı diğer çalışanlarla iletişim sorunları yaşarlar, ekip geliştiremezler, alt gruplara yabancılaşırlar ve örgütlerine zarar verirler (Abbas ve Karage, 2015, s.32-33).

Sağllklı Narsizm: Narsist bireyler narsistik özellikleri doğrultusunda geliştirdikleri beğenilme isteği nedeniyle başarılı olma ihtiyacını diğerlerinden daha çok hissedebilirler. Bu ihtiyaçlarından kaynaklı olarak narsist bireylerin iş ve sosyal yaşamlarında toplum tarafından önemli olarak görülen bir konuma sahip olmak için çaba göstermeleri beklenmektedir (Kanten vd., 2015, s.369). Ayrica narsist bireyler zor olayları ve önemli görevleri diğerlerine karşı üstünlüklerini göstermek için bir fırsat olarak görebilirler. Narsist CEO'ların, büyüme, hisse fiyatlarını değerlendirebilme ve hissedar değerini yükseltme gibi olumlu sonuçlarla alakalı olarak daha fazla istekli oldukları ileri sürülmüştür. Bununla birlikte, aynı CEO'lar başarısızlık durumunda sorumluluğu üzerlerine alma konusunda diğerlerinden daha az istekli olmaktadır (Reina vd., 2014, s.959).

Nitekim narsistlerin, başkaları tarafından liderlik algısında öne çıkan bir yer işgal etmeleri muhtemeldir. Narsist bireylerin, güç, prestij, çekicilik gibi ihtiyaçları nedeniyle liderlik pozisyonları aramaları beklenirken başkalarını manipüle etme kabiliyetleri, hızlı, yüzeysel ilişkiler kurma becerileri bu amaçlarında onlara hizmet eder (Kets de Vries ve Miller, 1984, s.32).

Narsizmin sağlıklı ve sağlıksız yönleri ile bir ikilem içerdiği düşünülebilir. Campbell vd. (2011, s.272), narsist liderlerin, bir taraftan tutku, vizyon ve yeniliklerinden övgüyle söz edilirken diğer taraftan, empati eksikliği ve eleştiriye aşırı duyarlı oldukları için eleştirilmelerini, aynı kişilik konfigürasyonunun hem parlak hem de karanlık bir tarafı içerebilmesinin mümkün olabilmesiyle açıklamaktadırlar. Narsizm başlangıçta kendinden emin ve karizmatik bir görüntü çizerken zamanla, bu özellikler bir hak hissine ve hatalardan ders alamamaya dönüşebilmektedir.

Campbell vd. (2011, s.273)'e göre, liderlik, narsistlerin kendini geliştirme ve üstünlük ihtiyaçlarını karşılamaları için en uygun iş pozisyonu olduğundan, modern örgütlerde liderlik rollerinde narsistik kişilik özelliğine sahip bireylere sıkça rastlanmaktadır. Narsist liderlerin sağlıklı ve sağlıksız narsistik kişilik özellikleri örgütlerde değişim için önemli bir 
güçtür. Bu değişiklik, örgütlerin benzeri görülmemiş bir başarıya ulaşmasına neden olabileceği gibi narsistlerin görkemli öz görüşleri, kararlarını gerçekçi bir şekilde değerlendirmelerini önleyerek risk almalarına neden olabileceği için başarısızlıklara da neden olabilir (Campbell, 2004, s.298).

Bu nedenle narsizmi iyi ya da kötü olarak nitelendirmek yerine narsizmin farklı bileşenlerine odaklanmak faydalı görünmektedir (Campbell ve Foster, 2007); narsizmin sosyal ilişkileri başlatmak ve lider olmak gibi sosyal bağlamlarda ve kişinin kendi ve yetenekleri hakkında olumlu görüşe sahip olması gibi sonuç değişkenlerinde bazı yararları bulunmaktadır. Öte yandan ilişkileri sürdürebilme ve uzun vadeli karar verme gibi sosyal bağlamlarda ve doğru öz-bilgi gibi sonuç değişkenlerinde narsizmin bazı zararlarının bulunduğu söylenebilir.

Narsizm örgütlerde iş doyumu ve bireysel iş performansı üzerinde de etkili olabilmektedir. Araştırma bulguları narsizmin etkileri konusunda farklı sonuçlar içermektedir.

Narsizm ile iş doyumu arasındaki ilişkiyi ölçen bazı araştırma sonuçlarına göre çalışanların narsizm düzeyleri arttıkça iş doyumlarınında arttığı tespit edilmiştir (Abbas ve Kant, 2017, s.13; Abbas ve Kant, 2017b, s.259; Abbas ve Karage, 2015, s.38).

Aksine narsistik kişilik özelliklerine sahip bireylerin şişirilmiş benlik görüşlerinin, kendileri için daha iyi iş alternatifleri olduğunu düşünmelerini sağlamasından dolayı narsist çalışanların daha düşük iş doyum düzeyine sahip olduğu yönünde araştırma sonuçlarına ulaşıldığını görmekte mümkündür (Mathieu, 2013, s.651; Mathieu vd., 2014, s.83).

Benzer şekilde literatürde narsizmin iş performansı üzerinde temel bir etkisinin olup olmadığı da açı değildir. Bu ilişkinin işin karmaşıklığı, çalışma arkadaşları ve müşterilerle yakın kişisel ilişkilerin sürdürülme düzeyi ile doğrudan ilgisi vardır; başkalarıyla yakın, birbirine bağımlı kişisel ilişkilerin sürdürülmesini gerektiren mesleklerde narsistlerin diğerlerini sömürme ve hak sahibi olma isteği, ilişkilerde sorunlara ve sonuç olarak da iş performansının düşmesine neden olabilir (Campbell vd., 2011, s.275-276).

Narsist bireylerin yüksek derecede aşırı güvenleri, kendileri hakkında şişirilmiş beceri ve yetenek tahminleri ile başarılı olmak için yüksek risk 
alma eğilimleri bireysel performanslarını olumsuz etkileyebilir (Campbell, 2004, s.299) veya narsist bireylerde baskın görünen başarılı olma ve statü elde etme ihtiyacı, amaçlarına ulaşabilmeleri için yüksek performans göstermelerine neden olabilir.

\section{Narsizmin İş Doyumu ve Bireysel Performans Üzerindeki Etkisi Üzerine Bir Araştırma}

Çalışmanın uygulama aşamasında, çalışanların narsistik kişilik özelliklerinin iş doyumları ve bireysel iş performansları üzerindeki etkisi incelenmektedir.

\section{Araştırma Modeli ve Hipotezleri}

Araştırmanın modeli, katılımcıların narsistik kişilik düzeyleri ile bireysel performans, iş doyumu ve demografik özellikleri arasındaki ilişkileri ölçmek üzere şekil 1'de kurulmuştur. Araştırma hipotezleri ise şu şekildedir.

H1: Narsistik kişilik düzeyi bireysel iş performansını etkilemektedir.

H2: Narsistik kişilik düzeyi içsel doyumu etkilemektedir.

H3: Narsistik kişilik düzeyi dışsal doyumu etkilemektedir.

H4: Narsistik kişilik düzeyi ile demografik özellikler arasında anlamlı farklılıklar vardır.

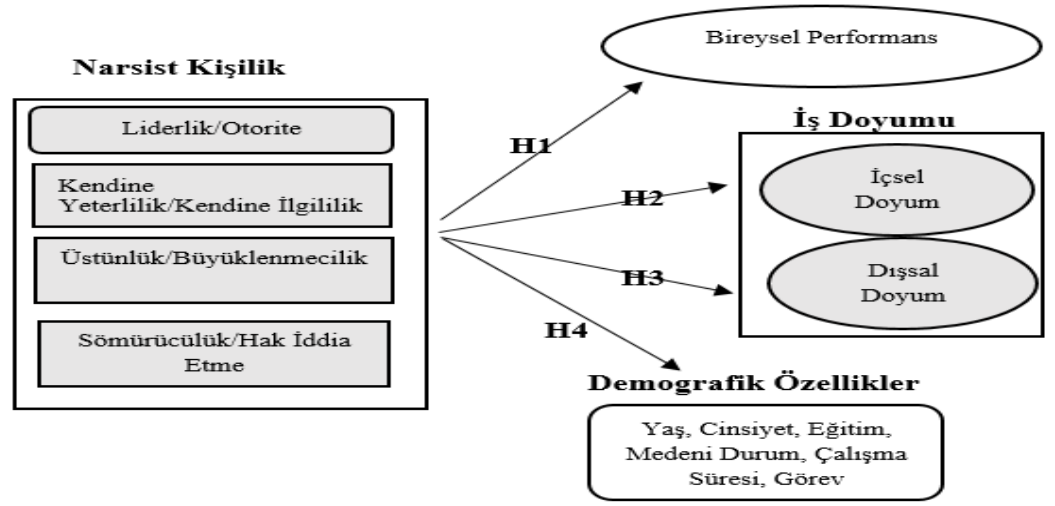

Şekil 1.Araştırmanın Teorik Modeli 


\section{Örneklem}

Araştırma, Tokat ilinde tekstil sektöründe faaliyet gösteren işletmelerde uygulanmıştır. Evrenin yaklaşık 600 çalışan olduğu bilgisi alınmış ve toplamda 350 anket dağıtılmıştır. Dağıtılan anketlerden 320'sinin geri dönüşü sağlanmış, 9 anket eksik doldurulduğundan araştırmaya dahil edilmemiştir. Araştırmaya dahil edilen anket sayısı 311 olmuştur. Örneklemin evreni temsil etme özelliği oldukça yüksektir. Verilerin elde edilmesinde yüz yüze anket yöntemi kullanılmıştır. Anket form uygulaması 1-15 Mart 2018 tarihleri arasında yapılmıştır.

\section{Araştırmada Kullanılan Ölçekler}

Narsistik Kişilik Envanteri; Araştırmada kullanılan ölçek; ilk olarak Raskin ve Hall tarafından 1979 yılında geliştirilmiş 40 maddelik NPI (Narsistik Kişilik Envanteri) ölçeğinin Ames ve arkadaşları tarafından (2006) oluşturulan 16 maddelik kısa formunun Atay (2009) tarafından Türkçe'ye uyarlanan çalışmasından alınmıştır. Ames ve arkadaşları tarafından yapılan çalışmada 16 maddelik NPI (Narsistik Kişilik Envanteri) kısa formunun güvenirlilik katsayısı $\alpha=, 670$ bulunurken Atay (2009)'ın Türkçe uyarlama çalışmasında güvenirlik katsayısı $\alpha=, 627$ olarak bulunmuştur (Atay, 2009, s.190). Bu çalışma için genel ölçek güvenirlik katsayısı $\alpha=, 781$ dir. Atay'ın (2009, s.191) uyarlama çalışmasında NPI-16 (Narsistik Kişilik Envanterini) teşhircilik, üstünlük, otorite, hak iddia etme, sömürücülük, kendine yeterlilik olmak üzere altı faktörlü bir yapı kullandığı görülmüştür. Bu çalışmada yapılan keşfedici faktör analizi sonucunda dört faktörlü bir yapı elde edilmiştir. Nitekim, Emmons (1987, s.13), narsizmi NPI (Narsistik Kişilik Envanteri) uyumluluk esasına göre dört farklı boyutta tanımlamıştır. Bu boyutlar; liderlik/otorite, kendine yeterlilik/kendine ilgililik, üstünlük/büyüklenmecilik ve sömürücülük/hak iddia etme boyutlarıdır (Emmons, 1987, s.13; Cihangiroğlu vd., 2015, s.4). Bu çalışmada keşfedici faktör analizi sonucunda elde edilen dört faktörlü yapıda Emmons'un dört boyutlu tanımlanması kullanılmıştır. Ölçekte 5'li Likert kullanılmış 1-Kesinlikle katılmıyorum, 5- Kesinlikle katılıyorum şeklinde puanlandırılmıştır. Narsistik Kişilik Envanteri (NPI-16) faktör analizi ve faktör yükleri ise Tablo 1'de gösterilmektedir. 
Tablo 1. Narsistik Kişilik Envanteri (NPI-16) Faktör Analizi

\begin{tabular}{|c|c|c|c|c|c|}
\hline & L/O & $\mathrm{K} / \mathrm{K}$ & $\ddot{\mathbf{U}} / \mathbf{B}$ & $\mathrm{S} / \mathrm{H}$ & Ort \\
\hline 4-İnsanlar üzerinde otorite kurmaktan hoşlanırım. & 742 & & & & 2,7 \\
\hline $\begin{array}{l}\text { 12-İnsanlar daima otoritemi kabul ediyor } \\
\text { görünürler. }\end{array}$ & ,657 & & & & 2,9 \\
\hline 8-Her zaman ne yaptığımı bilirim. & & 682 & & & 3,7 \\
\hline 13-İnsanları istediğim her şeye inandırabilirim. & & 448 & & & 3,0 \\
\hline 14-Kendi kendime yeterim. & & 646 & & & 3,5 \\
\hline 15-Önemli bir insan olacağım. & &, 503 & & & 3,3 \\
\hline $\begin{array}{l}\text { 1-İyi biri olduğumu biliyorum, çünkü herkes böyle } \\
\text { söyler. }\end{array}$ & & & 690 & & 3,6 \\
\hline 2-İlgi merkezi olmayı severim. & & & 785 & & 2,8 \\
\hline 3-Özel biri olduğumu düşünüyorum. & & & 605 & & 3,0 \\
\hline 7-Genellikle fırsatını bulduğumda şov yaparım. & & & ,728 & & 2,4 \\
\hline 11-İlgi merkezi olmaktan hoşlanırım. & & & 778 & & 2,8 \\
\hline 16-Sıra dışı biriyim. & & & ,616 & & 2,9 \\
\hline 5-İnsanları kolayca manipüle ederim. & & & &, 529 & 2,8 \\
\hline 6-Layık olduğum saygıyı görmekte 1srarcıyımdır. & & & & ,539 & 3,0 \\
\hline 9-Herkes hikayelerimi dinlemekten hoşlanır. & & & & ,716 & 3,0 \\
\hline 10-İnsanlardan çok şey beklerim. & & & & 604 & 2,9 \\
\hline $\begin{array}{l}\text { 12-İnsanlar daima otoritemi kabul ediyor } \\
\text { görünürler. }\end{array}$ & & & & 657 & 2,9 \\
\hline
\end{tabular}

$\mathrm{L} / \mathrm{O}=$ Liderlik/Otorite $\quad \mathrm{K} / \mathrm{K}=$ Kendine Yeterlilik/Kendine Ilgililik

$\ddot{U} / B=$ Üstünlük/Büyüklenmecilik $S / H=$ Sömürücülük/Hak İddia Etme

Tablo 1'de araştırmada kullanılan NPI-16 Narsistik Kişilik Envanterinin faktör yapısını doğrulamak için keşfedici faktör analizi uygulanmış ve neticede dört alt boyuta ulaşılmıştır. Bu boyutlar liderlik/otorite, kendine yeterlilik/kendine ilgililik, üstünlük/büyüklenmecilik ve sömürücülük/hak iddia etmedir. Her alt boyutun faktör yükleri değeri ise en düşük ,448 en yüksek ,785 arasında değerler almaktadır.

Tablo 2. Narsistik Kişilik Envanteri Alt Boyutlar Güvenirlik ve Varyans Değerleri

\begin{tabular}{lcc}
\hline Narsistik Kişilik Envanteri Alt Boyutlar & $\boldsymbol{\alpha}=$ =Cronbach Alpha & Kümülatif Varyans \\
\hline Liderlik/Otorite &, 704 & 24,809 \\
Kendine Yeterlilik/Kendine İlgililik &, 771 & 36,799 \\
Üstünlük/Büyüklenmecilik &, 774 & 48,627 \\
Sömürücülük/Hak İddia Etme &, 773 & 57,836 \\
Genel Ölçek (Narsistik Kişilik Envanteri) &, 781 & 57,836 \\
\hline
\end{tabular}

$K M O=, 878$ Bartlett's Test of Sphericity Chi-Square $=1,61013 \mathrm{df}=120$ sig $=, 000$ 
Tablo 2'de Narsistik Kişilik Envanteri alt boyutlarına ilişkin güvenirlik cronbach alpha katsayısı ile dört alt boyutun varyans değerleri yer almaktadır. Kendine yeterlilik/kendine ilgililik, üstünlük/büyüklenmecilik, sömürücülük/hak iddia etme ve Liderlik/Otorite alt boyutlarına ilişkin elde edilen cronbach alpha değerleri narsistik kişilik envanteri alt boyutlarının kabul edilebilir düzeyde güvenilir olduğunu göstermektedir. Dört boyutun toplam varyansı açılama oranı ise \% 57,836'dır.

İş Doyum Ölçeği; Araştırmada kullanılan iş doyum ölçeği, Türkiye'de kullanımı yaygın olan, geçerlilik ve güvenirliliği birçok çalışma ile test edilmiş Minnesota iş doyum ölçeğidir.

Tablo 3. İş Doyum Ölçeği Faktör Analizi

\begin{tabular}{|c|c|c|}
\hline İçse & D./Dişsal D. & Ort. \\
\hline 1-Beni her zaman meşgul etmesi bakımından. &, 546 & 3,4 \\
\hline 2-Bağımsız çalışma imkanının olması bakımından. & ,656 & 3,3 \\
\hline 3-Ara sıra değişik şeyler yapabilme imkanı bakımından. & ,655 & 3,3 \\
\hline 4-Toplumda saygın bir kişi olma şansını bana vermesi bakımından. & ,703 & 3,5 \\
\hline 7-Vicdani bir sorumluluk taşıma şansını bana vermesi yönünden. &, 520 & 3,4 \\
\hline 8-Bana garantili bir gelecek sağlaması yönünden. & 600 & 3,3 \\
\hline 9-Başkaları için bir şeyler yapabildiğimi hissetmem yönünden. & 670 & 3,0 \\
\hline 10-Kişileri yönlendirmek için fırsat vermesi yönünden. & ,674 & 2,8 \\
\hline 11-Kendi yeteneklerimle bir şeyler yapabilme şansı vermesi yönünden. & ,717 & 3,0 \\
\hline $\begin{array}{l}\text { 15.Kendi fikir-kanaatlerimi rahatça kullanma imkanı vermesi yönün- } \\
\text { den. }\end{array}$ & ,686 & 3,4 \\
\hline 16-Çalışma saatleri yönünden. & 490 & 3,0 \\
\hline $\begin{array}{l}\text { 20-Mesleğimi yaparken kendi yöntemlerimi kullanabilme imkanı ver- } \\
\text { mesi yönünden. }\end{array}$ & ,754 & 3,1 \\
\hline 5-Yöneticinin emrindeki kişileri iyi yönetmesi bakımından. & 647 & 3,2 \\
\hline 12-İşimle ilgili alınan kararları uygulamaya konması yönünden. & ,709 & 2,9 \\
\hline 13-Yaptığım iş karşılığı aldığım ücret yönünden. & ,523 & 3,4 \\
\hline 14-Terfi imkanının olması yönünden. & 407 & 3,5 \\
\hline 17-Çalışma arkadaşlarının birbirleriyle anlaşması yönünden. & ,647 & 3,4 \\
\hline 18-Yaptığım iç karşılığında takdir edilmem yönünden. & ,527 & 3,3 \\
\hline 19-Yaptığım iş karşıllı̆ında duyduğum başarı hissi yönünden. & ,730 & 3,3 \\
\hline 17-Çalışma arkadaşlarının birbirleriyle anlaşması yönünden. & ,754 & 3,6 \\
\hline
\end{tabular}

Ölçeğin ilk olarak Türkçe uyarlama çalışması Baycan (1985) tarafından yapılmıştır. Minnesota iş doyum ölçeği içsel iş doyumu ve dişsal iş doyumu olarak iki boyutta değerlendirilmektedir. Ölçek cevaplandırıl- 
masında 5'li likert kullanılmış 1-Hiç Memnun Değilim, 2-Memnun Değilim, 3-Kararsızım, 4-Memnunum, 5-Çok Memnunum şeklinde puanlandırılmıştır.

İş doyumu faktör analizi sonucunda içsel iş doyumu boyutunun faktör yükleri en düşük ,490 en yüksek ,754 arasında değerler almıştır. Dışsal iş doyumu alt boyutunun ise en düşük ,407 ile en yüksek ,754 arasında değerler aldığı görülmüştür.

Tablo 4. İş Doyum Ölçeği Alt Boyutlar Güvenirlik ve Varyans Değerleri

\begin{tabular}{lcc}
\hline Minnesota İş Doyum Ölçeği & $\alpha=$ Cronbach Alpha & Kümülatif Varyans \\
\hline İçsel Doyum &, 865 & 32,990 \\
Dişsal Doyum &, 825 & 47,120 \\
Genel İş Doyumu &, 914 & 47,120 \\
\hline$K M O=, 906$ Bartlett's Test of Sphericity Chi-Square $=2,77313 \mathrm{df}=190$ sig $=, 000$
\end{tabular}

Tablo 4'te Minnesota iş doyum ölçeği alt boyutları güvenirlik ve varyans değerleri verilmektedir. İçsel ve dişsal iş doyumu alt boyutlarının yüksek düzeyde güvenirlik değerlerine sahip olduğu görülmektedir. Ölçek genel güvenirlik cronbach alpha katsayısı ise $\alpha=, 914^{\prime}$ tür. İki boyutun toplam varyansın \% 47,120'sini temsil ettiği görülmektedir.

Bireysel Performans Ölçeği; Bireysel performans ölçeği ilk olarak Kirkman ve Rosen (1999) tarafından geliştirilmiş olup daha sonra Sigler ve Pearson (2000) tarafından 4 maddeden oluşturulmuş ve çalışanların bireysel performansını ölçmeye yönelik bir ölçektir.

\section{Tablo 5. Bireysel Performansı Faktör Analizi}

\begin{tabular}{lcc}
\hline & Faktör & Ort. \\
\hline 1- Görevlerimi zamanında tamamlarım. &, 546 & 4,0 \\
2- Sunduğum hizmet kalitesinde standartlara fazlası ile &, 854 & 3,9 \\
ulaştı̆̆ımdan eminim. &, 733 & 4,0 \\
3- Bir problem gündeme geldiğinde en hızlı şekilde çözüm üretirim. &, 854 & 3,9 \\
4- İş hedeflerime fazlasıyla ulaşırım. &, \\
\hline
\end{tabular}

Bireysel Performans ölçeği Türkiye'de yaygın kullanılan geçerlilik ve güvenirliliği test edilmiş bir ölçektir. Ölçekte 5'li Likert kullanılmış 1Kesinlikle katılmıyorum, 5- Kesinlikle katıliyorum şeklinde pu- 
anlandırılmıştır. Tablo 5'de bireysel iş perfomansı faktör analizi sonucunda faktör yüklerinin en düşük ,546 en yüksek ,854 arasında değerler aldığı görülmektedir.

Tablo 6. Bireysel Performans Ölçeği Güvenirlik ve Varyans Değerleri

\begin{tabular}{lcc}
\hline Bireysel Performans Ölçeği & $\alpha=$ Cronbach Alpha & Kümülatif Varyans \\
\hline Bireysel Performans Ölçeği Genel Ölçek &, 742 & 57,334 \\
\hline$K M O=, 725$ Bartlett's Test of Sphericity Chi-Square $=327,316$ df $=6$ sig $=, 000$ &
\end{tabular}

Tablo 6'da Ölçeğe ilişkin güvenirlik analizi neticesinde Cronbach Alpha katsayısı $\alpha=, 742$ olarak bulunmuştur. Bu değere göre, ölçek bu araştırma için güvenilir bir ölçektir. Ayrıca dört ifadenin toplam varyansın \%57,334'ünü temsil ettiği görülmektedir.

\section{Demografik Özellikler ve Anlamlı Farklılıklar}

Araştırmanın bu bölümünde katılımciların demografik özelliklerine ilişkin bilgiler ve narsistik kişilik özellikleri ile katılımcıların demografik özellikleri arasında anlamlı bir farklılık bulunup bulunmadığına ilişkin analizler yer almaktadır. Veri analizlerine geçmeden önce, kullanılan ölçeklerin çarpıklık (Skewness) ve basıklık (kurtosis) değerleri -2 ile 2 arasında değerler aldığı için normal dağılımda kullanılan T-testi ve ANOVA analizleri tercih edilmiştir.

Tablo 7'de katılımcıların demografik özelliklerine ilişkin bulgular görülmektedir. Elde edilen bulgulara göre katılmıcıların \% 75,6'sı erkek (235 kişi), \% 24,4'ü (76 kişi) kadın iken \% 76,5'i (236 kişi) evli, \% 23,5'i (75 kişi) bekardır. Çalışanların büyük çoğunlu idari işlerde, yardımcı hizmetlerde ve işçi statüsünde görev yapmaktadır (\% 26,4, \% 24,8, \% 25,4). Katılımcıların \% 30,5'i (95 kişi) lise, \% 26,4'ü (82 kişi) önlisans düzeyinde eğitime tabidir. Katılımcıların çalışma süresi \% 33 (105 kişi) 5-8 yıl, \% 32,5 (101 kişi) 1-4 yıl'dır. 
Tablo 7. Demografik Özelliklere İlişkin Bulgular

\begin{tabular}{|c|c|c|c|c|c|}
\hline Yaş & Sayı & $\%$ & Eğitim & Sayı & $\%$ \\
\hline $20-25$ yaş & 33 & 10,6 & İlköğretim & 69 & 22,2 \\
\hline $26-35$ yaş & 98 & 31,5 & Lise & 95 & 30,5 \\
\hline $36-45$ yaş & 114 & 36,6 & Önlisans & 82 & 26,4 \\
\hline $46-55$ yaş & 59 & 19 & Lisans & 57 & 18,3 \\
\hline 55yaş üstü & 7 & 2,3 & Lisansüstü & 8 & 2,6 \\
\hline Çalışma Süresi & Sayı & $\%$ & Medeni Durum & Sayı & $\%$ \\
\hline 1 yıldan az & 28 & 9 & Evli & 236 & 76,5 \\
\hline 1-4 Yil & 101 & 32,5 & Bekâr & 75 & 23,5 \\
\hline 5-8 Yil & 105 & 33,8 & Cinsiyet & Say1 & $\%$ \\
\hline 9-12 Y1l & 33 & 10,6 & Erkek & 235 & 75,6 \\
\hline 13Yil üstü & 44 & 14,1 & Kadın & 76 & 24,4 \\
\hline Görev & Sayı & $\%$ & & & \\
\hline İdari İşler & 75 & 24,8 & \multirow{5}{*}{\multicolumn{3}{|c|}{$N=311$}} \\
\hline Teknik İşler & 70 & 19,2 & & & \\
\hline Yardımcı Hizmetler & 79 & 26,4 & & & \\
\hline Yönetici & 11 & 4,2 & & & \\
\hline İşçi & 76 & 25,4 & & & \\
\hline
\end{tabular}

Tablo 8'de narsistik kişilik özelliği boyutları ile katılımcıların cinsiyet ve medeni durumları arasındaki farklılıkları incelemeye yönelik t-Testi sonuçları görülmektedir.

Tablo 8. Cinsiyet, Medeni Durum t-Testi Analizi

\begin{tabular}{lll}
\hline & \multicolumn{1}{c}{ Cinsiyet } & Medeni Durum \\
\hline Liderlik/Otorite & $\mathrm{p}=, 018^{*}(\mathrm{t}=-2,381)$ & $\mathrm{p}=, 110(\mathrm{t}=-1,603)$ \\
\hline Kendine Yeterlilik/Kendine İlg. & $\mathrm{p}=, 001^{*}(\mathrm{t}=-3,463)$ & $\mathrm{p}=, 000^{*}(\mathrm{t}=-3,590)$ \\
\hline Üstünlük/Büyüklenmecilik & $\mathrm{p}=, 000^{*}(\mathrm{t}=-3,707)$ & $\mathrm{p}=, 003^{*}(\mathrm{t}=-2,999)$ \\
\hline Sömürücülük/Hak İddia Etme & $\mathrm{p}=, 000^{*}(\mathrm{t}=-3,729)$ & $\mathrm{p}=, 000^{*}(\mathrm{t}=-3,684)$ \\
\hline
\end{tabular}

Anlamlı farklılığın nedeni ise kadınların narsistik kişilik eğilim alt boyut puanlarının erkek katılımcılara göre yüksek olmasıdır. Yine katılımcların medeni durumu ile narsistik kişilik özellikleri alt boyutları olan kendine yeterlilik/kendine ilgililik, üstünlük/büyüklenmecilik ve sömürücülük/hak iddia etme arasında anlamlı farklılıklar bulunmuştur $(\mathrm{p}<0,05)$. Anlamlı farklılığın ise bekarların narsistik kişilik alt boyut puanlarının evlilere göre yüksek olmasından kaynaklandığı tespit edilmiştir. 
Tablo 9. Çalışma Süresi, Eğitim ANOVA Analizi

\begin{tabular}{lll}
\hline & Çalışma Süresi & Eğitim \\
\hline Liderlik/Otorite & $\mathrm{p}=, 063(\mathrm{~F}=2,257)$ & $\mathrm{p}=, 352(\mathrm{~F}=1,109)$ \\
\hline Kendine Yeterlilik/Kendine İlg. & $\mathrm{p}=, 008^{*}(\mathrm{~F}=3,526)$ & $\mathrm{p}=, 491(\mathrm{~F}=, 856)$ \\
\hline Üstünlük/Büyüklenmecilik & $\mathrm{p}=, 055(\mathrm{~F}=-2,341)$ & $\mathrm{p}=, 270(\mathrm{~F}=1,299)$ \\
\hline Sömürücülük/Hak İddia Etme & $\mathrm{p}=, 081(\mathrm{~F}=2,101)$ & $\mathrm{p}=, 606(\mathrm{~F}=, 681)$ \\
\hline
\end{tabular}

Tablo 9'da katılımcıların çalışma süresi ve eğitim düzeyi ile narsistik kişilik özellikleri alt boyutları arasındaki anlamlı farklılıkların tespiti için yapılan ANOVA analiz sonuçları yer almaktadır. Analizler neticesinde katılımcıların çalışma süresi ile kendine yeterlilik/kendine ilgililik alt boyutu arasında anlamlı farklılık bulunmuştur $(\mathrm{p}<0,05)$. Yapılan post hocTukey testi sonucunda 1 yıldan az çalışma süresine sahip olan katılımcların kendine yeterlilik/kendine ilgililik puanlarının 4-6 yıl çalışma süresine sahip olan katılımcılara göre yüksek olduğu görülmüştür. Katılımcıların eğitim düzeyleri ile narsist kişilik özellikleri arasında ise anlamlı bir farklılığa rastlanmamıştır $(p>0,05)$.

Tablo 10. Yaş, Görev ANOVA Analizi

\begin{tabular}{lll}
\hline & \multicolumn{1}{c}{ Yaş } & Görev \\
\hline Liderlik/Otorite & $\mathrm{p}=, 074(\mathrm{~F}=2,158)$ & $\mathrm{p}=, 000^{*}(\mathrm{~F}=6,366)$ \\
\hline Kendine Yeterlilik/Kendine İlg. & $\mathrm{p}=, 004^{*}(\mathrm{~F}=3,859)$ & $\mathrm{p}=, 000^{*}(\mathrm{~F}=5,858)$ \\
\hline Üstünlük/Büyüklenmecilik & $\mathrm{p}=, 001^{*}(\mathrm{~F}=4,870)$ & $\mathrm{p}=, 000^{*}(\mathrm{~F}=5,938)$ \\
\hline Sömürücülük/Hak İddia Etme & $\mathrm{p}=, 000^{*}(\mathrm{~F}=6,345)$ & $\mathrm{p}=, 000^{*}(\mathrm{~F}=8,598)$ \\
\hline
\end{tabular}

Tablo 10 'da katılımcıların yaş ve statüleri ile narsistik kişilik özelliği arasındaki anlamlı farka ilişkin analiz sonuçları yer almaktadır. Katılımcıların yaşları ile narsistik kişilik özelliklerinin bazı alt boyutları arasında anlamlı farklılıklar bulunmuştur $(\mathrm{p}<0,05)$. Yapılan post hocTukey testi sonucunda anlamlı farklılıkların şu şekilde olduğu görülmüştür. 26-35 yaş grubu katılımcıların kendine yeterlilik/kendine ilgililik puanları 36-45 ve 46-55 yaş grubuna göre yüksektir. 20-25 yaş gurubu katılımcıların üstünlük/büyüklenmecilik puanları 36-45, 46-55 ve 55 yaş üstü katılımclara göre yüksektir. 20-25 yaş grubu katılımcların sömürücülük/hak iddia etme puanları $36-45$ ve $46-55$ yaş grubuna göre daha yüksektir. 
Yine katılımcıların görevleri ile narsistik kişilik özelliği alt boyutları arasında anlamlı farklılıklara rastlanmıştır $(\mathrm{p}<0,05)$. Anlamlı farklılıklar ise şu şekildedir. İşçi statüsünde çalışan katılımcıların teknik işlerde görev yapan katılımcılara göre liderlik/otorite puanları yüksek çıkmıştır. İdari işlerde görev yapan katılımcıların teknik işlerde görev yapan katılımcılara göre kendine yeterlilik/kendine ilgililik, üstünlük/büyüklenmecilik ve sömürücülük/hak iddia etme puanlarının yüksek olduğu tespit edilmiştir.

Böylece elde edilen sonuçlara göre H4 hipotezi desteklenmiştir.

Tablo 11. Narsistik Kişilik, İş Doyumu ve Bireysel Performans Korelasyon İlişkisi

$\begin{array}{llllllll}1 & 2 & 3 & 4 & 5 & 6 & 7 & 8\end{array}$

\begin{tabular}{|c|c|c|c|c|c|c|c|c|}
\hline 1.Liderlik/Otorite(N) & 1 & & & & $224^{*}$ & $228^{*}$ & $228^{*}$ & $191^{*}$ \\
\hline $\begin{array}{l}\text { 2.Kendine Yeter- } \\
\text { lilik/Kendine İlg.(N) }\end{array}$ & $413^{*}$ & 1 & & & ,263* & ,210* & ,248* & $240^{*}$ \\
\hline 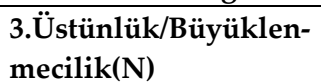 & $651^{*}$ & $404^{*}$ & 1 & & $297^{*}$ & $248^{*}$ & ,293* & $263^{*}$ \\
\hline $\begin{array}{l}\text { 4.Sömürücülük/Hak } \\
\text { id.Etme(N) }\end{array}$ & $607^{*}$ & $471^{*}$ & ,710* & 1 & $256^{*}$ & $194^{*}$ & ,249* & $192^{*}$ \\
\hline 5.İçsel İş Doyum(İD) & & & & & 1 & $753^{*}$ & , $947^{*}$ & $263^{*}$ \\
\hline 6.Dışsal İş Doyum(İD) & & & & & & 1 & $916^{*}$ & $271^{*}$ \\
\hline 7.Genel İş Doyum & & & & & & & 1 & $287^{*}$ \\
\hline 8. Bireysel Performans & & & & & & & & 1 \\
\hline
\end{tabular}

*=0,01 düzeyinde anlamlılık $\dot{I} D=\dot{I}_{\text {Ş Doyum }}$ N=Narsistik Kişilik

Tablo 11 narsistik kişilik özelliği, iş doyumu ve bireysel iş performansı korelasyon ilişkisini göstermektedir. Analizler neticesinde narsistik kişilik özellikleri alt boyutları ile iş doyumu boyutları arasında istatistiksel olarak pozitif yönlü anlamlı bir ilişkinin olduğunu söylemek mümkündür $(p<0,01)$. Liderlik/otorite boyutu ile iş doyumu arasında çok zayıf düzeyde anlamlı bir ilişki bulunmaktadır $(\mathrm{r}=, 228)$. Kendine yeterlilik/kendine ilgililik boyutu ile iş doyumu arasında çok zayıf düzeyde anlamlı bir ilişki bulunmaktadır $(\mathrm{r}=, 248)$. Üstünlük/büyüklenmecilik ile iş doyumu arasında zayıf düzeyde anlamlı bir ilişki vardır $(\mathrm{r}=, 293)$. Sömürücülük/hak iddia etme ile iş doyumu arasında çok zayıf düzeyde anlamlı bir ilişki bulunmaktadır $(\mathrm{r}=, 249)$. 
Liderlik/otorite, kendine yeterlilik/kendine ilgililik ve sömürücülük /hak idda etme alt boyutları ile bireysel performans arasında çok zayıf düzeyde pozitif yönlü anlamlı bir ilişki söz konusudur. Üstünlük/büyüklenmecilik alt boyutu ile bireysel performans arasındaki ilişki ise zayıf düzeyde pozitif yönlü ve anlamlıdır.

Tablo 12. Bireysel Performans Çoklu Regresyon Analizi Bulgular

\begin{tabular}{lcccc}
\hline \multicolumn{1}{c}{\begin{tabular}{l} 
Model :a.Predictors (Contant), Bireysel \\
\multicolumn{1}{c}{ Performans }
\end{tabular}} & \multicolumn{2}{c}{ Coefficient } & \multicolumn{2}{c}{ Tolerans } \\
Beta $(\boldsymbol{\beta})$ & T & Sig. & VIF \\
\hline Liderlik/Otorite &, 025 &, 324 &, 746 & $, 522-1,915$ \\
Kendine yeterlilik/Kendine İlgililik &, 172 & 2,727 &, $007^{*}$ & $, 751-1,331$ \\
Üstünlük/Büyüklenmecilik &, 171 & 2,014 &, $045^{*}$ & $, 418-2,314$ \\
Sömürücülük/Hak İddia Etme &,- 025 &,- 302 &, 763 & $, 432-2,314$ \\
\hline
\end{tabular}

$\mathrm{R}=, 286 \mathrm{R}^{2}=, 082 \mathrm{~F}=6,816 \quad$ Durbin Watson:1,947 $\mathrm{p}=, 000$

Tablo 12' de narsistik kişilik boyutlarının bireysel performansa olan etkisini incelemeye yönelik çoklu regrasyon analiz sonuçları yer almaktadır. Elde edilen bulgulara göre narsistik kişilik özellikleri boyutlarının bireysel performansa etkisi istatiksel olarak anlamlıdır $(\mathrm{p}=, 000)$. Narsistik kişilik özellikleri boyutları bireysel performansın \%8,2'sini açıklamaktadır. Narsistik kişilik özellikleri boyutlarından kendine yeterlilik/kendine ilgililik ve üstünlük/büyüklenmecilik boyutlarının bireysel performansa yaptığ etki istatistiksel olarak anlamladır $(\mathrm{p}<0,05)$.

Böylece H1 hipotezi desteklenmiştir.

Tablo 13. İçsel İş Doyumu Çoklu Regresyon Analizi Bulguları

\begin{tabular}{lcccc}
\hline \multicolumn{1}{c}{\begin{tabular}{c} 
Model :a.Predictors (Contant), İçsel İş \\
\multicolumn{1}{c}{ Doyumu }
\end{tabular}} & \multicolumn{2}{c}{ Coefficient } & \multicolumn{2}{c}{ Tolerans } \\
& Beta $(\beta)$ & T & Sig. & VIF \\
\hline Liderlik/Otorite &, 003 &, 046 &, 963 & $, 522-1,915$ \\
Kendine yeterlilik/Kendine İlgililik &, 164 & 2,637 &, $009^{*}$ & $, 751-1,331$ \\
Üstünlük/Büyüklenmecilik &, 207 & 2,486 &, $013^{*}$ & $, 418-2,314$ \\
Sömürücülük/Hak İddia Etme &, 368 &, 368 &, 713 & $, 432-2,314$ \\
\hline
\end{tabular}

$\mathrm{R}=, 336 \mathrm{R}^{2}=, 101 \mathrm{~F}=9,748 \quad$ Durbin Watson: $1,441 \mathrm{p}=, 000$

Tablo 13'de narsistik kişilik boyutlarının içsel iş doyumu etkisini incelmeye yönelik yapılan çoklu regrasyon analiz sonuçları görülmektedir. Elde edilen bulgulara narsistik kişilik özellikleri boyutlarının içsel iş doyumuna yaptığ1 etki istatistiksel olarak anlamlıdır $(p=, 000)$. Narsistik 
kişilik boyutları içsel iş doyumunun \% 10,1'ini açılamaktadır. Narsistik kişilik boyutlarından kendine yeterlilik/kendine ilgililik boyutu ve üstünlük/büyüklenmecilik boyutunun içsel iş doyumuna yaptığı etki istatistiksel olarak anlamlıdır $(\mathrm{p}<0,05)$.

Böylece H2 hipotezi desteklenmiştir.

Tablo 14. Dışsal İş Doyumu Çoklu Regresyon Analizi Bulguları

\begin{tabular}{|c|c|c|c|c|}
\hline \multirow{2}{*}{$\begin{array}{c}\text { Model :a.Predictors (Contant), } \\
\text { Dişsal İş Doyumu }\end{array}$} & \multicolumn{2}{|c|}{ Coefficient } & \multicolumn{2}{|c|}{ Tolerans } \\
\hline & Beta $(\beta)$ & $\mathbf{T}$ & Sig. & VIF \\
\hline Liderlik/Otorite & ,093 & 1,225 & 222 & ,522-1,915 \\
\hline Kendine yeterlilik/Kendine İlgililik & 122 & 1,931 & 054 & ,751-1,331 \\
\hline Üstünlük/Büyüklenmecilik & , 165 & 1,943 & 053 & $, 418-2,314$ \\
\hline Sömürücülük/Hak İddia Etme & ,368 &,- 442 & 659 & $, 432-2,314$ \\
\hline $\mathrm{R}=, 284 \mathrm{R}^{2}=, 068 \quad \mathrm{~F}=6,698$ & \multicolumn{4}{|c|}{ Durbin Watson:1,574 $p=, 000$} \\
\hline
\end{tabular}

Tablo 14'de narsistik kişilik boyutlarının dışsal iş doyumuna etkisini incelemeye yönelik yapılan çoklu regrasyon analizi görülmektedir. Elde edilen bulgulara göre, narsistik kişilik boyutlarının dişsal iş doyumuna yaptığı etki istatistiksel olarak anlamlıdır $(p=, 000)$. Narsistik kişilik dışsal iş doyumunun \% 6,8'ini açıklamaktadır.

Böylece H3 hipotezi desteklenmiştir.

\section{Sonuç}

Bir kişilik bozukluğu olarak görülen narsizm, örgüt içerisinde çalışan davranışlarında ve çalışanlar arasındaki ilişkilerde etkili olabilmektedir. Son yıllarda narsizm, narsist çalışanların gerek üretkenlik dışı davranışlara neden olarak örgütlere verdiği zararlar gerekse başarma ihtiyaçlarının kariyer hedefleri üzerindeki olumlu etkileri nedeniyle örgütler için tanınması ve diğer örgütsel değişkenlerle ilişkisi anlaşılması gereken olgulardan biri olarak kabul görmüştür.

Literatürde narsizmle farklı örgütsel değişkenler arasındaki ilişkileri ortaya koymak için yapılmış çok sayıda araştırma bulumaktadır. Bu çalışmada ise narsizmin iş doyumu ve bireysel performans üzerindeki etkisi araştırılmıştır.

Narsistik kişilik özelliklerinin çalışanların iş doyumuna ve bireysel performansına etkisini inceleyen bu araştırmada bazı anlamlı etkiler 
bulunmuştur. Araştırma bulgularına göre, narsistik kişilik özellikleri ile iş doyumu ve bireysel performans arasında pozitif yönlü bir ilişki tespit edilmiştir. Narsistik kişilik düzeyindeki bir birimlik artış bireysel performans üzerinde 0,113 birimlik artışa neden olmaktadır. Yine narsistik kişilik düzeyindeki bir birimlik artışın içsel iş doyumunda 0,101 birimlik, dışsal iş doyumunda 0,068 birimlik bir artışa neden olduğu görülmüştür. Çalışanların narsistik kişilik düzeyi arttıkça çalışanlarda iş doyumunun ve bireysel performansın arttığını bu çalışma sonuçları için söylemek mümkündür. Araştırma da elde edilen bu sonuç bazı araştırmalarla örtüşmektedir (Abbas ve Kant, 2017, s.13; Abbas ve Kant, 2017b, s.259; Abbas ve Karage, 2015, s.38).

Araştırma sonuçları, narsist çalışanların beğenilme, başarı, statü ihtiyaçlarının örgütlerde kendilerine verilen görevleri yerine getirirken yüksek performans sergilemelerine hatta lider pozisyonu almalarına bu sayade de iş doyumlarında artışa neden olabileceği şeklinde yorumlanabilir.

Çalışmada elde edilen diğer bir sonuç, çalışanların demografik özelliklerine göre narsistik kişilik düzeylerinde bazı farklılıkların olmasıdır. Elde edilen sonuçlarda kadınların ve bekar katılımcıların narsistik kişilik düzeylerinin daha yüksek olduğu görülmüştür. Yine işçi statüsünde çalışan katılımcıların teknik işlerde görev yapan katılımcılara göre liderlik/otorite puanları yüksek çıkmıştır. İdari işlerde görev yapan katılımcıların teknik işlerde görev yapan katılımcılara göre kendine yeterlilik/kendine ilgililik, üstünlük/büyüklenmecilik ve sömürücülük/hak iddia etme puanlarının yüksek olduğu tespit edilmiştir. Katılımcıların yaşlarına bakıldığında ise, bazı anlamlılıklara rastlamak mümkündür. Örneğin, 26-35 yaş grubu katılımcıların kendine yeterlilik/kendine ilgililik puanları 36-45 ve 46-55 yaş grubuna göre yüksektir. 20-25 yaş gurubu katılımcıların üstünlük/büyüklenmecilik puanları 36-45, 46-55 ve 55 yaş üstü katılımcılara göre yüksektir. 20-25 yaş grubu katılımcıların sömürücülük/hak iddia etme puanları $36-45$ ve $46-55$ yaş grubuna göre daha yüksektir. 1 yıldan az çalışma süresine sahip olan katılımcıların kendine yeterlilik/kendine ilgililik puanlarının 4-6 yıl çalışma süresine sahip olan katılımclara göre yüksek olduğu ise elde edilen diğer sonuçlar arasındadır. Narsistik kişilik düzeyi ile eğitim düzeyi arasında ise herhangi bir anlamlı farklılığa rastlanmamıştır. 
Araştırma sonuçları, örgütlerde özellikle olumlu narsistik kişilik özelliklerinin ön plana çıkarılmasının örgüt hedeflerine ulaşılmasına sağlayacağı katkının anlaşılması açısından değerlidir. Araştırma sonuçlarının tüm çalışanlara yönelik genelleştirilmesi, benzer araştırmaların farklı bölge ve sektörlerde uygulanması araştırma bulgularının geçerliliğini artıracaktır. Ayrıca gelecek çalışmalarda örgütlerde sağlıklı ve sağlıksız boyutlarıyla giderek önemini artıran narsizmin, farklı örgütsel değişkenlerle özellikle liderlikle ilişkisini ölçmeye yönelik araştırmaların yapılmasının önemli olduğu düşünülmektedir. 


\title{
EXTENDED ABSTRACT
}

\section{A Field Study on the Effect of Narcissism on Job Satisfaction and Individual Performance}

\author{
Alper Gürer - Gamze Ebru Çiftçi \\ Kırkkale University - Hitit University
}

The effects of narcissism and narcissistic behavior on the personal disorders in psychology are also observed in the business world. The reason for this is that the narcissistic personality traits, which are seen as one of the important sources of conflict in social relations, have different effects in the organizational context. Although there are positive results within these effects, narcissism appears as a negative behavior type.

In fact, it is generally accepted that narcissism is a personality disorder resulting from trauma in early childhood. The American Psychiatric Association describes Narcissism as a pattern of perpetual magnitude of self admiration, a need for appreciation, and a pattern which created by lack of empathy (Narcissistic Personality Disorder DSM-5). Campbell et al. (2011, p. 269) considered narcissism a a structure with three components; identity, interpersonal relations and self-regulation strategies. Identity is; narcissistic self, positivity, originality, arrogance, feeling of having right, power and desire of respect. Interpersonal relationships are associated with low empathy and emotional affinity. This component includes shallow relationships ranging from exciting and intriguing to manipulative and exploitative. Self regulation strategies are narcissistic strategies, like looking for opportunities to attract attention and awaken admiration, selfworthy of others' successes and playing in personal relationships, which are developed to maintain inflated self-views

Narcissism in the Narcissistic Personality Inventory (NPI), which is the most commonly used narcissism scale, is evaluated in four dimensions: Exploitation; a skillful belief in manipulating people and the right to do so. Leadership / Authority; the belief that one has an extraordinary ability to influence others, a general preference for leadership and authority roles. Superiority / grandiosity; the belief that one is better than others. 
Finally self-sufficiency / self-interest; a high feeling of arrogance and the belief that he is special (Emmons, 1987, cited by Smith, 2017). According to Campbell et al. (2011, p.273), since leadership is the most appropriate job position for narcissists to meet the needs of self-development and superiority, individuals with narcissistic personality traits in leadership roles in modern organizations are frequently encountered. Narcissistic leaders' healthy and unhealthy narcissistic personality traits are an important force for change in organizations. This change not only may lead to unprecedented success of organizations, but also may lead to failures, since grand self views of narcissists may lead to take risks by preventing them from realistically evaluating their decisions (Campbell, 2004, p.298). Therefore, instead of describing narcissism as good or bad, it seems useful to focus on different components of narcissism (Campbell and Foster, 2007).

\section{Method}

Within the framework of the studies conducted, this research was designed to examine the relationship between the narcissistic personality traits and the job satisfaction and performance of the employees. In this context, the survey method was selected for the research and the prepared questionnaire was applied in the enterprises operating in the textile sector in the province of Tokat. The questionnaire that applied to 311 employees included in the study, where approximately 600 employees were employed in the industry. In order to carry out the study, three different scales were used which their validity and reliability analyzes had been performed. These scales are as follows;

Narcissistic Personality Inventory; the scale used in the research; is given from Atay (2009)'s Turkish Language adaptation study, which is firstly developed by Raskin and Hall in 1979 with 40-item NPI (Narcissistic Personality Inventory) and 16 item short form created by Ames and friends (2006). Job Satisfaction Scale; The job satisfaction scale used in the study, is Minnesota job satisfaction scale which is commonly used in Turkey and the validity and reliability have been tested in many studies. Individual Performance Scale; The individual performance scale used in the 
study was firstly developed by Kirkman and Rosen (1999) and was composed of 4 items by Sigler and Pearson (2000) is a scale toward measuring the individual performance of employees.

\section{Results}

In this study which examines the effect of narcissistic personality traits on job satisfaction and individual performance, some significant results have been reached. According to the findings of the study, a positive relationship was found between narcissistic personality traits and job satisfaction and individual performance. A unit increase in narcissistic personality level leads to an increase of 0.111 units on individual performance. Again, it has been observed that a unit increase in narcissistic personality level leads to an increase of 0.110 units in internal job satisfaction and 0.068 units in external job satisfaction. As the narcissistic personality level of employees increases, it is possible to say that job satisfaction and individual performance increase in employees in terms of the results of this study. Another result of the study is that there are some differences in the level of narcissistic personality according to the demographic characteristics of the employees. In the results obtained, it was observed that women and single participants had higher narcissistic personality levels. Again, employees who work in worker position have higher scores on leadership / authority with respect to employees in technical jobs. Participants in administrative positions were found to have higher self-sufficiency / self-efficacy, superiority / grandiosity and exploitation / claim points than the participants in technical jobs. When we look at the age of the participants, it is possible to find some meaningfulness. For example, the self-sufficiency / self-efficacy scores of the 26-35 age group are higher than the 3645 and 46-55 age group. The participants in the 20-25 age group were higher than the participants who were 36-45, 46-55 and 55-above years old in terms of superiority/grandiosity. Participants of the 20-25 age group have more exploitation / claim points than the 36-45 and 46-55 age groups. Among the other results obtained in the study is that the self-sufficiency / self-efficacy scores of the participants who have less than 1 year of work time are higher than the participants who have 4-6 years working time. 
There was no significant difference between the narcissistic personality level and the educational level of the participants.

\section{Kaynakça / References}

Abbas, S. M. S. ve Kant, V. (2017). Gender as moderator of narcissism and job satisfaction: study on comparative assessment of banking and fmcg sectors in Delhi NCR. International Journal of Research in Business Studies and Management, 4(1), 7-15.

Abbas, S. M. S. ve Kant, V. (2017b). AN empirical study on narcissism and job satisfaction among employees in Delhi NCR banks. Paripex Indian Journal Of Research, 6(5), 256-260.

Abbas, S. M. S. ve Karage, A. I. (2015). Narcissism and job satisfaction: an exploratory study of organizations in north eastern Nigeria. Research Journal of Commerce \& Behavioural Science, 5(1), 32-41.

Ames, D. R., Rose, P. ve Anderson, C. P. (2006). The NPI-16 as a short measure of narcissism. Journal of Research in Personality, 40, 440450.

Atay, S. (2009). Narsistik kişilik envanteri'nin Türkçe'ye standardizasyonu. Gazi Üniversitesi İktisadi ve İdari Bilimler Fakültesi Dergisi,11(1), 181-196.

Baycan, A. (1985). An analysis of several aspects of job satisfaction between different occupational groups. Yayınlanmamış Doktora Tezi, Boğaziçi Üniversitesi, İstanbul, Türkiye.

Brown, R. P., Budzek, K. ve Tamborski, M. (2009). On the meaning and measure of narcissism. Personality and Social Psychology Bulletin, 35(7), 951-964.

Bushman, B. J. ve Baumeister, R. F. (1998). Threatened egotism, narcissism, self-esteem, and direct and displaced aggression: Does self-love or self-hate lead to violence?. Journal of Personality and Social Psychology, 75(1), 219-229.

Campbell, W. K., Hoffman, B. J., Campbell, S. M. ve Marchisio, G. (2011). Narcissism in organizational contexts. Human Resource Management Review, 21, 268-284. 
Campbell, W. K. ve Foster, J., D. (2007). The narcissistic self: Background, an extended agency model, and ongoing controversies. In C. Sedikides, \& S. Spencer (Eds.), Frontiers of social psychology. The self (p. 115-138). New York: Psychology Press.

Campbell, W. K., Goodie, A. S. ve Foster, J. D. (2004). Narcissism, confidence, and risk attitude. Journal of Behavioral Decision Making, 17, 297-311.

Cihangiroğlu, N., Teke, A., Uzuntarla, Y. ve Uğrak, U. (2015). Narsist kişilik eğilimleri ile kurumsal bağlllık düzeyleri arasındaki ilişkinin analizi. Yönetim ve Uygulamaları Araştırması Dergisi, 13(1), 1-18.

Emmons, R. A. (1987). Narcissism: Theory and measurement, Journal of Personality and Social Psychology, 52(1), 11-17.

Farber, B. A. (1983). Stress and burnout in the human services professions. New York, Pergamon Press.

Higgs, M. (2009). The good, the bad and the ugly: Leadership and narcissism. Journal of Change Management, 9(2), 165-178.

Johnson, R. E., Silverman, S. B., Shyamsunder, A., Swee, H. Y., Rodopman, O. B., Cho, E. ve Bauer, J. (2010). Acting superior but actually inferior?: Correlates and consequences of workplace arrogance. $\mathrm{Hu}$ man Performance, 23(5), 403-427.

Judge, T. A., LePine, J. A. ve Rich, B. L. (2006). Loving yourself abundantly: Relationship of the narcissistic personality to self- and other perceptions of workplace deviance, leadership, and task and contextual performance. Journal of Applied Psychology, 91(4), 762-776.

Kanten, P., Yeşiltaş, M. ve Arslan, R. (2015). Kişiliğin karanlık yönünün üretkenlik karşıtı iş davranışlarına etkisinde psikolojik sözleşmenin düzenleyici rolü. Atatürk Üniversitesi İktisadi ve İdari Bilimler Dergisi, 29(2), 365-391.

Kanten, P. (2014). Narsistik kişilik özelliğinin üretkenlik karşıtı iş davranışlarına etkisinde örgüt ikliminin düzenleyici rolü. İ.Ü. İşletme İktisadi Enstitüsü Yönetim Dergisi, 25(76), 160-184.

Kets de Vries, M. ve Miller, D. (1984). The neurotic behavior of organizations. San Francisco: Jossey-Bass. 
Mathieu, C., Neumann, C. S., Hare, R. D. ve Babiak, P. (2014). A dark side of leadership: Corporate psychopathy and its influence on employee well-being and job satisfaction. Personality and Individual Differences, 59, 83-88.

Mathieu, C. (2013). Personality and job satisfaction: The role of narcissism, Personality and Individual Differences, 55, 650-654.

Millon, T. (1981). Disorders of personalitv, DSM-III: Axis II. New York: Wilev.

Narcissistic Personality Disorder DSM-5. https://www.theravive.com/therapedia/narcissistic-personality-disorder-dsm--5301.81-(f60.81), (13.01.2018).

Penney, L. M. ve Spector, P. E. (2002). Narcissism and counterproductive work behavior: do bigger egos mean bigger problems?. International Journal Of Selection And Assessment, 10(1/2), 126-134.

Philipson, I. (1985). Gender and narcissism, Psychology of Women Quarterly, 9, 213-228.

Reina, C.S., Zhang, Z. ve Peterson, S. J. (2014). CEO grandiose narcissism and firm performance: the role of organizational identification. The Leadership Quarterly, 25(5), 958-971.

Sigler, T.H. ve Pearson, C. M. (2000). Creating an empowering culture: Examining the relationship between organizational culture and perceptions of empowerment. Journal of Quality Management, 5, 2752.

Smith, J. G. (2017). The narcissistic salesperson: a framework of their relationships with job satisfaction, organizational commitment, and customer orientation. Atlantic Marketing Journal, 6(2), Article 1. https://digitalcommons.kennesaw.edu/amj/vol6/iss2/1

Qureshi, S. U., Ashfaq, J., Hassan, M. U. ve Imdadullah, M. (2015). Impact of Extroversion and Narcissism on in Role and Extra Role Performance: Moderating Role of Impression Management Motives. Pakistan Journal of Commerce and Social Sciences, 9(1), 96-119. 


\section{Kaynakça Bilgisi / Citation Information}

Gürer, A. ve Çiftçi, G. E. (2019). Narsizmin iş doyumu ve bireysel performans üzerindeki etkisi üzerine bir alan araștırması. OPUSUluslararası Toplum Araştırmaları Dergisi, 11(18), 78-103. DOI: 10.26466/opus.534813 